\title{
The effect of storytelling on anxiety and behavioral disorders in children undergoing surgery: a randomized controlled trial
}

This article was published in the following Dove Press journal:

Pediatric Health, Medicine and Therapeutics

\author{
Zohreh Sekhavatpour' \\ Narges Khanjani ${ }^{2}$ \\ Tayebeh Reyhani $^{3}$ \\ Sogol Ghaffari ${ }^{4}$ \\ Maryam Dastoorpoor ${ }^{5}$ \\ 'Department of Pediatric Nursing, \\ Anesthesiology, School of Paramedicine, \\ Dezful University of Medical Sciences, \\ Dezful, Iran; ${ }^{2}$ Department of \\ Epidemiology, Neurology Research \\ Center, Kerman University of Medical \\ Sciences, Kerman, Iran; ${ }^{3}$ Department of \\ Nursing, Faculty of Nursing, Mashhad \\ University of Medical Sciences, Mashhad, \\ Iran; ${ }^{4}$ Department of Psychologist, Dezful \\ University of Medical Sciences, Dezful, \\ Iran; ${ }^{5}$ Department of Epidemiology and \\ Biostatistics, Menopause Andropause \\ Research Center, Ahvaz Jundishapur \\ University of Medical Sciences, Ahvaz, \\ Iran
}

Background: One of the most frightening procedures for children is surgery. This study aimed to assess the effect of animated illustrated stories on anxiety and behavioral disorders in children after surgery.

Methods: In this randomized controlled clinical trial (RCT), 60 children between 4 and 8 years who went through adenotonsillectomy were divided into two groups based on random numbers. In the intervention group, animated illustrated books were read for the children by the researcher, for 30 mins, on the night before surgery. Child's anxiety was measured using the Revised Children's Manifest Anxiety Scale (RCMAS) and Behavioral Disorder questionnaire (a researcher-made tool) before and 10 days after the book reading. Data were analyzed using descriptive statistics and the non-parametric Mann-Whitney $U$ test and Wilcoxon signed-rank test.

Results: The results showed that mean scores of physiological anxiety $(P$-value $<0.001)$, social concerns/concentration $(P$-value $=0.012)$, and total anxiety $(P$-value $<0.001)$, except worry/oversensitivity $(P$-value $=0.140)$, statistically significantly decreased in the intervention group after book reading, but mean total anxiety and its three dimensions did not show statistically significant differences before and after treatment in the control group $(P$ value $>0.05)$. Mean scores of the Behavioral Disorder questionnaire significantly decreased in the intervention group after book reading $(P$-value $=0.001)$, but significantly increased in the control group $(P$-value $<0.001)$.

Conclusion: The results showed that reading animated illustrated books could be effective in reducing anxiety and behavioral disorders in children after surgery. It seems that these books could be a new and creative way to distract children and can be used as supportive care.

Keywords: anxiety, behavioral disorders, children's surgery, storytelling

\section{Background}

About $30 \%$ of the children are hospitalized at least once during childhood. ${ }^{1}$ In the United States, more than 5 million children undergo surgery annually, among whom $50 \%$ to $75 \%$ experience considerable fear and anxiety before surgery. ${ }^{2}$ Many factors cause anxiety among children before surgery. These factors might be fear from physical injury, pain, mutilation, or death; separation from parents and communicating with strangers in the absence of family, mistrust in adults, fear of the unknown, uncertainty about the limitations and acceptable behavior, and loss of independence or control. ${ }^{3}$ Preoperative anxiety is often associated with undesirable post-surgical
Correspondence: Maryam Dastoorpoor Department of Epidemiology and Biostatistics, Menopause Andropause Research Center, Ahvaz Jundishapur University of Medical Sciences, Golestan

St., Ahvaz, Iran, Ahvaz, Iran

$\mathrm{Tel} / \mathrm{Fax}+98613336754$

Email mdastoorpour@yahoo.com 
results, and behavioral disorders in the recovery phase may occur. These disorders include continuous anxiety and discomfort, phobia or unrealistic fear, nightmares, eating disorders, enuresis, delayed recovery and discharge, increased heart rate, respiratory rate, and blood pressure, nausea, restlessness, malaise, and fatigue. ${ }^{4,5}$ A study by Moura et al showed $42.0 \%$ of the children hospitalized for elective outpatient surgery, in 2013-2014, in Goiania, Brazil, had preoperative anxiety that was related to their age and socioeconomic status. ${ }^{5}$

Chow et al (2015) showed the effectiveness of audiovisual interventions in reducing preoperative anxiety among children undergoing elective surgery, ${ }^{6}$ and Aminabadi et al (2011) showed that visual storytelling had a statistically significant effect on reducing pain and anxiety among children who visited a dentist. ${ }^{7}$ Dahmani et al (2014) also showed that postoperative delirium in preschool children can be prevented by using psychological approaches and sedative medication together. ${ }^{8}$

In this trial, we experimented the effect of reading animated illustrated book stories on reducing preoperative anxiety in children.

\section{Methods}

\section{The study population and sampling}

This study was a randomized controlled trial, which studied the effect of animated illustrated books on anxiety and behavioral disorders in children undergoing adenotonsillectomy in 2015.

The sample included 60 children aged 4 to 8 years old, hospitalized for 2 days in the surgery wards of large hospitals in Dezful (Iran) in 2015, who were chosen by convenient sampling.

\section{Inclusion and exclusion criteria}

The included children had to be 4-8 years old, without chronic diseases (such as cancer, liver, or kidney disease), or hearing and speaking problems, and without a history of surgery and hospitalization, central nervous system diseases, or mental illnesses such as depression. The parents of these children had to be present at the time of hospitalization and consent for their child's participation.

Children who did not cooperate in listening to the stories or earned a score greater than 6 (from 9) in the pathometer subscale were excluded. The pathometer subscale is one of the subscales of the questionnaire used in this study and shows the responder's dishonesty.

\section{Sample size}

In order to determine the sample size, due to the lack of a similar study in this field, a pilot study was conducted on ten children in the intervention group and ten children in the control group. Then, by using the $\mathrm{G}^{*}$ Power software ${ }^{9}$ assuming the influence coefficient $=0.74$ (calculated based on the total anxiety index from the pilot), $\alpha=0.05$ and power $=0.8$, the sample size was estimated to be 30 children in the intervention group and 30 in the control group.

The recruited children were assigned into two groups randomly, based on the table of random numbers.

\section{Data collection tools}

Data were collected by a demographic information questionnaire, the standard RCMAS or Revised Children Manifest Anxiety Scale ${ }^{10}$ and a researcher-made questionnaire for behavioral disorders. The demographic questionnaire included questions about age, sex, birth date, birth order, child's literacy, the educational level and occupation of parents, family income, health insurance status, living place, number of family members, and the child's psychological support.

The child's literacy was determined by asking one of the parents.

The Behavioral Disorder Questionnaire was a researcher-made tool. As there was no suitable tool available, we decided to build a questionnaire ourselves. In order to build this questionnaire, a conceptual chart was drawn and questions were designed based on a literature review of recent related articles and expert opinion. The face and content validity of this questionnaire were approved by 10 academics and experts, including specialized consultants. The Cronbach's alpha was 0.87 and $\mathrm{ICC}=0.93$.

The RCMAS contains 37 items including 28 items that measure anxiety and 9 other items that assess the subject's dishonest responses (the pathometer subscale). In this tool, children are asked to answer each of the items with yes/no, and then each item is scored zero or one.

A total anxiety score is computed based on 28 items, which are divided into 3 anxiety subscales: physiological anxiety, obsessive concerns, and distracting thoughts and fears. The remaining nine items on the RCMAS constitute the Lie subscale for dishonest responses (Table 1).

Participants with pathometer scores higher than six were excluded from the study. The reliability and validity of the RCMAS have been investigated, and the Cronbach's 
Table I The subscales of the Revised Children's Manifest Anxiety Scale questionnaire

\begin{tabular}{|c|c|c|}
\hline Subscales & $\begin{array}{l}\text { No. of } \\
\text { items }\end{array}$ & Description \\
\hline $\begin{array}{l}\text { Physiological } \\
\text { anxiety }\end{array}$ & 10 items & It is about somatic manifestations of anxiety such as sleep difficulties, nausea and fatigue, worry, or oversensitivity \\
\hline $\begin{array}{l}\text { Obsessive } \\
\text { concerns }\end{array}$ & I I items & $\begin{array}{l}\text { It measures obsessive concerns about a variety of things, most of which are typically vague and ill-defined, as well } \\
\text { as fears about being hurt or emotionally isolated, and social concerns or concentration }\end{array}$ \\
\hline Distractions & 7 items & It measures distracting thoughts or fears that have a social or interpersonal nature. \\
\hline Pathometer & 9 items & This is the Lie subscale and determines dishonest responses. \\
\hline Total items & 37 & \\
\hline
\end{tabular}

alpha coefficient was reported to be $>0.7$ in previous studies. ${ }^{11}$

The Behavioral Disorder questionnaire used in this study was a researcher-designed checklist that consisted of 22 questions about retrograde behavior, separation anxiety, phobia, panic attacks, anger, moral swings, depression, limb jerks, thumb sucking, nail chewing, excuse bringing, pain, loss of focus, lying, and impaired speech. Answers to questions were based on 5 options: never, rarely, sometimes, often, or always. A child with a higher score was supposed to have more behavioral disorders. The questionnaire was designed by reviewing several books and articles, and the content validity was commented on and approved by 10 pediatricians, and psychology specialists from Dezful University of Medical Sciences. The reliability of the scale was assessed again in this study; its intra-class correlation coefficient (ICC) was 0.80 and its Cronbach's alpha was 0.74 .

\section{Intervention}

Initially, the researcher explained the purpose of the study in 10 to 15 mins face-to-face for parents. Then, written informed consent was obtained and the demographic information questionnaire was completed by interviewing the parents or the child's medical reports.

The reason for choosing participants from the 4- to 8year-old range was based on Piaget's theory of cognitive development that considers children have intuitive and cognitive thinking based on visual aspects at this age. ${ }^{12}$

An animated illustrated story was read in the intervention group for 30 mins the night before the operation. The intervention was performed on the night before surgery because the child was admitted just the day before surgery and researchers did not have access to the child sooner. In order to avoid bias in the anxiety and behavioral disorders questionnaire, this questionnaire was completed by the evaluation team including a pediatric clinical psychologist, nurse, and researcher before surgery, in the ward and 10 days after surgery by phone call, and interviewing the mother.

In this study, the story was told by the researcher for children. This story was taken from the Mental fitness protocol of Powell et $\mathrm{al}^{12}$ and was designed in four parts: the first part included providing basic information. In this section, two types of information were given to the child. First, procedural information that contained primary information about the surgery and all the procedures from entry until exit from the hospital. Information such as actions before surgery, during hospitalization, and sensory information, including emotions like pain, itching, and burning that the child may experience during the treatment process and conditions that will occur immediately after surgery, like wound site pain, nausea, numbness, and pain were explained to the child. The second part included the behavior guidelines. In this part, behaviors such as effective breathing before anesthesia, useful and harmful movements before and after treatment were read for children, and practically, the behavioral role was played and the child was asked to repeat it. These guidelines were taught to children before surgery by the researcher. The third part included cognitive interventions. In this part of the book, the researcher showed pictures of the operating theater and the equipment including the anesthesia mask, and vital sign's monitor clips which children might fear from. The researcher changed the child's attitude towards this equipment so that they understood the painlessness of this equipment. In this phase, in order to make children believe that they can do this, pictures of similaraged children performing the same things were shown. The book was designed in a three-dimensional fashion. After telling the story, the children were asked to perform tasks such as move displaced figures to the right place on the storyboard and describe things. They were also asked to narrate the story in plain language.

The fourth part included excitement interventions. In all phases in this booklet, the children were asked to 
clearly express their emotions and excitements, like anxiety or fear and state what they are worried about or which levels scared them. Hence, it was focused more on items that the child had fear. The control group only received routine care.

\section{Statistical analysis}

Frequency was reported for categorical variables, and means and standard deviations were calculated for continuous variables.

Data normality was assessed by the KolmogorovSmirnov test. The results of this test showed that the anxiety score and its dimensions, and also the total score of behavioral disorders were positively skewed and not normally distributed. Therefore, in order to compare the mean scores of these variables before and after the intervention, the Wilcoxon signed-rank test was used, and to compare scores between the two intervention and control groups, the Mann-Whitney $U$ test was used. Also, the non-parametric Chi-square test was used to compare categorical demographic variables such as child's gender, education, and parents' education in the two groups under study.

Data analysis was performed by SPSS 16 (IBM Corp. Released 2009. SPSS Statistics for Windows, Armonk, NY).

\section{Results}

Table 2 shows the demographic details of the children who participated in this study. The results of Mann-Whitney $U$ and Chi-squared tests showed no statistically significant difference between demographic variables in the intervention and control groups.

The Wilcoxon signed-rank test results showed that the mean scores of physiological anxiety $(P$-value $<0.001)$, social concerns/concentration $(P$-value $=0.012)$, and total anxiety $(P$-value $<0.001)$ declined significantly in the intervention group, after the intervention. But in the worry/ oversensitivity dimension, it was not statistically significant $(P$-value $=0.140)$. However, the mean score of total anxiety $(P$-value $=0.165)$ and its three dimensions including physiological anxiety $(P$-value $=0.169)$, worry/oversensitivity $(P$-value $=0.283)$, and social concerns/concentration $(P$-value $=0.377)$ before and after the intervention did not show a statistically significant difference in the control group (Table 3).

The results show that the mean score of the behavioral disturbances significantly decreased in the intervention group after the intervention $(P$-value $=0.001)$. But, in the control group, the mean score of behavioral disturbances significantly increased $(P<0.001)$ (Table 3$)$.

Also, in order to assess the effect of intervention on anxiety and behavioral disturbances, the difference between before and after scores (after score minus before score) of anxiety criteria and behavioral disturbances were compared between the two groups, using Mann-Whitney $U$ test. As observed in Table 4, behavioral disturbances, all dimensions of anxiety and total anxiety, except worry/ oversensitivity, significantly decreased (negative scores) in the intervention group, after applying the intervention (Table 4).

\section{Discussion}

Anxiety before surgery and anesthesia in children can lead to severe mental pressure and negative psychological effects. ${ }^{13}$ Interventions aimed to reduce anxiety can help children cope with the situation.

Kain et al (2007) mentioned interventions to reduce anxiety in children and their parents before surgery. These interventions included prescribing a sedative before surgery, the presence of parents during the whole process of surgery and anesthesia, and providing appropriate informative preparation programs. ${ }^{14}$

A study by Cooper et al (2019) stated that storytelling is a very useful tool in health communication, and with the availability of high-speed Internet and affordable computer devices, it could be a valuable tool for children and their parents for decision making, reducing anxiety, and saving counseling time. ${ }^{15}$ Berghmans et al (2018) showed that after adenotonsillectomy, children often develop moderate and severe problems and sleep disturbances during the first 3 days after surgery, at home. Pre-operation problems and the need to know information were related with increased pain at home. These authors suggested that screening for these problems can help identify vulnerable children and prepare them by providing appropriate information, programs, and anti-drug treatments before the surgery. ${ }^{16}$

The results of Hatipoglu et al (2018) showed that providing visual and auditory information before anesthesia in children was very effective in reducing preoperative anxiety and behavioral changes, one week after discharge. ${ }^{17}$ The study by Aminabadi et al (2012) also showed that illustrated stories caused a significant reduction in pain perception and situational anxiety during dental treatment and improved the children's interaction with the dentist. ${ }^{7}$

A study by Gonçalves et al (2017) ${ }^{18}$ showed that visual storytelling reduced aggression in primary school children, 
Table 2 Distribution of demographic variables among study groups

\begin{tabular}{|c|c|c|c|c|}
\hline \multicolumn{2}{|l|}{ Variables } & Intervention group $^{\mathbf{a}}$ & Control group ${ }^{a}$ & $P$-value \\
\hline \multicolumn{2}{|l|}{ Age of children, $y$} & $5.93(1.48)$ & $6.60(1.40)$ & $0.079^{b}$ \\
\hline \multicolumn{2}{|l|}{ Age of mother, $y$} & $32.80(4.83)$ & $33.20(5.26)$ & $0.830^{\mathrm{b}}$ \\
\hline \multicolumn{2}{|l|}{ Family income, per month } & $587 \$(187)$ & $629 \$(219)$ & $0.468^{b}$ \\
\hline Gender & $\begin{array}{l}\text { Boy } \\
\text { Girl }\end{array}$ & $\begin{array}{l}18(60.0) \\
12(40.0)\end{array}$ & $\begin{array}{l}13(43.3) \\
17(56.7)\end{array}$ & $0.196^{c}$ \\
\hline Educational of children & $\begin{array}{l}\text { Out of school } \\
\text { In school }\end{array}$ & $\begin{array}{l}14(46.7) \\
16(53.3)\end{array}$ & $\begin{array}{l}13(43.3) \\
17(56.7)\end{array}$ & $0.795^{c}$ \\
\hline Mother's education & $\begin{array}{l}\text { Under diploma } \\
\text { Diploma and upper }\end{array}$ & $\begin{array}{l}10(33.3) \\
20(66.7)\end{array}$ & $\begin{array}{l}17(56.7) \\
13(43.3)\end{array}$ & $0.069^{c}$ \\
\hline Mother's employment & $\begin{array}{l}\text { Non-employed } \\
\text { Employed }\end{array}$ & $\begin{array}{l}26(86.7) \\
4(13.3)\end{array}$ & $\begin{array}{l}27(90.0) \\
3(10.0)\end{array}$ & $0.688^{c}$ \\
\hline Residence & $\begin{array}{l}\text { Rural } \\
\text { Urban }\end{array}$ & $\begin{array}{l}14(46.7) \\
16(53.3)\end{array}$ & $\begin{array}{l}18(60.0) \\
12(40.0)\end{array}$ & $0.301^{c}$ \\
\hline Health insurance & $\begin{array}{l}\text { Without insurance } \\
\text { With insurance }\end{array}$ & $\begin{array}{l}0(00.0) \\
30(100.0)\end{array}$ & $\begin{array}{l}0(00.0) \\
30(100.0)\end{array}$ & - \\
\hline Number of children in family & $\begin{array}{l}\text { I child } \\
2 \text { children } \\
\geq 3 \text { children }\end{array}$ & $\begin{array}{l}6(20.0) \\
16(53.3) \\
8(26.7)\end{array}$ & $\begin{array}{l}6(20.0) \\
16(53.3) \\
8(26.7)\end{array}$ & $>0.999^{c}$ \\
\hline Mental support of children & $\begin{array}{l}\text { No } \\
\text { Yes }\end{array}$ & $\begin{array}{l}0(00.0) \\
30(100.0)\end{array}$ & $\begin{array}{l}0(00.0) \\
30(100.0)\end{array}$ & $>0.999^{c}$ \\
\hline
\end{tabular}

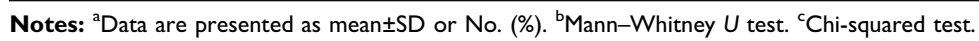

Table 3 Mean of anxiety and behavioral disturbances before and after intervention in intervention and control groups

\begin{tabular}{|c|c|c|c|c|}
\hline Variables & Group & Before intervention $^{a}$ & 10 day after intervention ${ }^{a}$ & $P$-value \\
\hline \multirow[t]{2}{*}{ Physiological anxiety } & Intervention group $(n=30)$ & $3.67 \pm 2.17$ & $2.60 \pm 1.89$ & $<0.001 *$ \\
\hline & Control groups $(n=30)$ & $2.73 \pm 1.91$ & $3.27 \pm 2.07$ & 0.169 \\
\hline \multirow[t]{2}{*}{ Worry/oversensitivity } & Intervention group $(n=30)$ & $5.93 \pm 2.45$ & $5.43 \pm 2.43$ & 0.140 \\
\hline & Control groups $(n=30)$ & $4.67 \pm 2.51$ & $5.33 \pm 2.32$ & 0.283 \\
\hline \multirow[t]{2}{*}{ Social concerns/concentration } & Intervention group $(n=30)$ & $1.63 \pm 1.16$ & $1.20 \pm 0.81$ & $0.012 *$ \\
\hline & Control groups $(n=30)$ & $1.27 \pm 1.36$ & $1.50 \pm 1.38$ & 0.377 \\
\hline \multirow[t]{2}{*}{ Total anxiety } & Intervention group $(n=30)$ & $11.23 \pm 4.74$ & $9.23 \pm 4.17$ & $<0.00 I^{*}$ \\
\hline & Control groups $(n=30)$ & $8.67 \pm 4.64$ & $10.10 \pm 4.76$ & 0.165 \\
\hline \multirow[t]{2}{*}{ Behavioral disturbances } & Intervention group $(n=30)$ & $46.20 \pm 9.00$ & $41.70 \pm 8.71$ & $0.00 I^{*}$ \\
\hline & Control groups $(n=30)$ & $40.53 \pm 7.87$ & $44.87 \pm 9.54$ & $<0.00 I^{*}$ \\
\hline
\end{tabular}

Notes: ${ }^{a}$ Data are presented as mean $\pm S D$. ${ }^{b}$ Wilcoxon signed-rank test. ${ }^{*}$-values significant at $\alpha$ level less than 0.05 .

and Moghimian et al (2019) ${ }^{19}$ stated that visual storytelling reduced the anxiety of patients before open-heart surgery.

The review done by Perry et al (2012) about preoperative interventional teaching strategies to reduce preoperative anxiety in children using age-appropriate educational interventions is in line with the present study and showed that preparation of children before surgery is a great way to reduce preoperative anxiety and postoperative behavioral disorders. In Perry et al's review, anxiety decreased by $91 \%$ in the intervention group compared to $81 \%$ in the 
Table 4 Mean differences of anxiety and behavioral disturbances before and after intervention ${ }^{\mathrm{a}}$

\begin{tabular}{|l|l|l|l|}
\hline Variables & Intervention group (after-before) $^{\mathbf{a}}$ & Control groups (after- before) $^{\mathbf{a}}$ & $\boldsymbol{P}_{\text {-value }}$ \\
\hline Physiological anxiety & $-1.07 \pm 1.17$ & $0.53 \pm 1.87$ & $<0.00 I^{*}$ \\
Worry/oversensitivity & $-0.50 \pm 1.68$ & $0.67 \pm 2.29$ & 0.169 \\
Social concerns/concentration & $-0.43 \pm 0.86$ & $0.23 \pm 1.25$ & $0.044^{*}$ \\
Total anxiety & $-2.00 \pm 2.43$ & $1.43 \pm 4.34$ & $<0.00 I^{*}$ \\
Behavioral disturbances & $-4.50 \pm 6.38$ & $4.33 \pm 5.21$ & $<0.00 I^{*}$ \\
\hline
\end{tabular}

Notes: ${ }^{a}$ Data are presented as mean \pm SD. ${ }^{b}$ Mann-Whitney $U$ test. *P-values significant at $\alpha$ level less than 0.05 .

control group. Their study also showed that children who received age-appropriate training had better data-processing, coping skills, experiences, and emotional control after surgery than children who had received routine daily interventions. These children also had less psychological problems, less anxiety in the recovery phase, and less risk of retrograde behavioral disorders, such as nightmares, separation anxiety, eating disorders, and enuresis after surgery, and were more compatible in all stages and needed less sedation and experienced less physical limitations. $^{2}$

Another study by Zarei et al (2013) about the effectiveness of storytelling on physiological anxiety, worry, and social anxiety in hospitalized school-age children suggests that storytelling could reduce all sub-scales of anxiety (RCMAS). These authors introduced storytelling as an effective, inexpensive method and the child's favorite non-pharmaceutical intervention. ${ }^{20}$ Tabrizi et al (2015) also evaluated the effect of preoperational education on reducing anxiety among children aged 8-10 years and showed that storytelling for children significantly reduced separation anxiety during anesthesia. ${ }^{21}$ Rice et al (2008) showed that educational programs that aimed at preoperative anxiety among children reduced their anxiety during hospitalization and caused stable vital signs. ${ }^{22}$ Messina et al (2014) tried to reduce children's anxiety before surgery by using clown therapy for distraction and significantly decreased anxiety among children who entered the operating room with the clown. ${ }^{23}$

In this study, we tried to increase children's awareness and distract children. Aytekin et al (2016) conducted a study, about the effect of preoperational distraction on postoperative anxiety in children and showed a $4.2 \%$ decrease in postoperative anxiety in children. ${ }^{24}$ Our results are also in line with the study done by Al-Khotani et al (2016), which was a clinical trial about the impact of audio-visual distraction during dental treatment on children's behavior. Al-Khotani's study showed a decrease in behavioral disorders and conditional anxiety. ${ }^{25}$
In this regard, Al-Yateem et al (2016) write that surgery can be considered as an aggressive experience in a child's life, and if not dealt with properly by health care professionals, it can lead to adverse consequences beyond surgery. Health care professionals should seek methods to reduce the anxiety associated with surgery, improve the experience of the child and parents, and prevent negative outcomes. This task was traditionally done with drug therapy, which may have negative side effects, and therefore non-medicinal methods should be sought. These authors conducted a randomized controlled trial and concluded that anxiety decreased in children undergoing day surgery that listened to visual storytelling. ${ }^{26}$

In the study done by Majzoobi et al (2013), mental preparation was effective on perioperational children's anxiety ${ }^{27}$ as well.

The reason for different results can be the different types of intervention (watching cartoons or playing computer games), different durations of intervention, and presence or non-presence of parents beside the child during the whole intervention.

The systematic review done by Hudson et al (2016) on more than 20 articles on the effect of perioperative interventions on pain and anxiety management during anesthesia showed that $30 \%$ of the studies considered perioperative interventions (audiovisual and relaxation-based intraoperative interventions) effective on pain and anxiety management, but, in about $50 \%$ of the studies, perioperative interventions had no significant effect. ${ }^{28}$

Gaskey showed that using images in the anesthetic visit before the operation could significantly decrease preoperative anxiety in adult patients. These patients were also less nervous and had a better knowledge about the anesthetic procedure. ${ }^{29}$ Our research showed that exposure to a three-dimensional image book significantly reduced anxiety during anesthesia. In this regard, the results of Fortier et al $(2015)^{30}$ and Batuman et al $(2016)^{31}$ found that showing an audiovisual program before the operation is a cheap method to decrease children's anxiety. 


\section{The strengths and limitations of the study}

The strengths of the study were the inclusion of an expert evaluating team to assess anxiety and behavioral disorders among children, including a pediatric psychologist, researcher, and nurse.

A limitation of this study was its small sample size because this study was conducted in winter and spring, when children went to school, and the number of children for surgery was less, compared to summer. Other limitations include using self-report questionnaires and not using objective measures for measuring pain or anxiety.

On the other hand, because of differences in children's intelligence, social class, attachment style, and parents' anxiety, generalization of these results to all other children in this age category should be performed with caution.

\section{Conclusion}

Pre-operative storytelling may be able to increase the child's familiarity with the environment, reduce the harmful effects of imminent stress, change the child's attitude towards the hospital environment, surgery, and operating theater, and decrease the child's fear and anxiety.

It is suggested that such programs be implemented in routine hospital programs and that nurses, as the most effective caregivers, play a main role in this regard.

\section{Ethics approval and consent to participate}

This study was approved by the Ethics Committee of Dezful University of Medical Sciences and the Ethic Code was IR. DUMS.REC.1394.4. The objectives of this study were explained for all parents by the researcher and written informed consent was obtained from the parents before commencement. This study was registered in the clinical trials registry of Iran (Code: IRCT2015082223704N1) on July 29, 2015.

\section{Data sharing statement}

The authors can share unidentified participant data on reasonable request. Some photos of the illustrated material used in this study can be made available to interested people as well. The data and material can be assessed through communication with the corresponding author, anytime.

\section{Acknowledgment}

The authors would like to thank all of the children who participated in the study and their parents. This study was financially supported by Dezful University of Medical Sciences, and Health Services.

\section{Disclosure}

The authors report no conflicts of interest in this work.

\section{References}

1. Smeltzer Suzanne CC, Bare Brenda G. Brunner S Text Book of Medical Surgical Nursing. Philadelphia: Lippincott Williams and Wilkins; 2004.

2. Perry JN, Hooper VD, Masiongale J. Reduction of preoperative anxiety in pediatric surgery patients using age-appropriate teaching interventions. $J$ PeriAnesthesia Nurs. 2012;27(2):69-81. doi:10.1016/j.jopan.2012.01.003

3. Ibanga AJ, Ibanga HB. Psychological Issues in Paediatric Surgery. Paediatric Surgery: A Comprehensive Text for Africa. Global Help. 2011. Available from: https://storage.googleapis.com/global-help-pub lications/books/help_pedsurgeryafrica14.pdf.

4. Felder-Puig R, Maksys A, Noestlinger C, et al. Using a children's book to prepare children and parents for elective ENT surgery: results of a randomized clinical trial. Int $J$ Pediatr Otorhinolaryngol. 2003;67(1):35-41.

5. Moura L, Dias IMG, Pereira LV. Prevalence and factors associated with preoperative anxiety in children aged 5-12 years. Rev Lat Am Enfermagem. 2016;(24)1-7.

6. Chow CH, Van Lieshout RJ, Schmidt LA, Dobson KG, Buckley N. Systematic review: audiovisual interventions for reducing preoperative anxiety in children undergoing elective surgery. $J$ Pediatr Psychol. 2015;41(2):182-203. doi:10.1093/jpepsy/jsv094

7. Aminabadi NA, Vafaei A, Erfanparast L, Oskouei SG, Jamali Z. Impact of pictorial story on pain perception, situational anxiety and behavior in children: a cognitive-behavioral schema. J Clin Pediatr Dent. 2011;36(2):127-132.

8. Dahmani S, Delivet H, Hilly J. Emergence delirium in children: an update. Curr Opin Anaesthesiol. 2014;27(3):309-315. doi:10.1097/ ACO.0000000000000076

9. Faul F, Erdfelder E, Lang A-G, Buchner A. G* Power 3: a flexible statistical power analysis program for the social, behavioral, and biomedical sciences. Behav Res Methods. 2007;39(2):175-191.

10. Boehnke K, Sillbereisen RK, Reynolds CR, Richmond BO. What I think and feel-German experience with the revised form of the children's manifest anxiety scale. Personality Individual Differences. 1986;7(4):553-560. doi:10.1016/0191-8869(86)90132-7

11. Baldwin JS, Dadds MR. Reliability and validity of parent and child versions of the multidimensional anxiety scale for children in community samples. J Am Acad Child Adolesc Psychiatry. 2007;46 (2):252-260. doi:10.1097/01.chi.0000246065.93200.a1

12. Powell R, Scott NW, Manyande A, et al. Psychological preparation and postoperative outcomes for adults undergoing surgery under general anaesthesia. Cochrane Lib. 2016(5):1-280. doi:10.1002/ 14651858.CD008646.pub2

13. Memarzadeh M, Hosseinpour M, Aflakian H. Evaluation of playing room on preoperative anxiety of 2-6 years old children in AL-Zahra hospital. Iran J Surg. 2006;14(4):10-16.

14. Kain ZN, Caldwell-Andrews AA, Mayes LC, et al. Family-centered preparation for surgery improves perioperative outcomes in ChildrenA randomized controlled trial. Anesthesiol. 2007;106 (1):65-74. doi:10.1097/00000542-200701000-00013

15. Cooper K, Hatfield E, Yeomans J. Animated stories of medical error as a means of teaching undergraduates patient safety: an evaluation study. Perspect Med Educ. 2019;8(2):118-122.

16. Berghmans JM, Poley MJ, van der Ende J, et al. Association between children's emotional/behavioral problems before adenotonsillectomy and postoperative pain scores at home. Pediatric Anesthesia. 2018;28 (9):803-812. doi:10.1111/pan.13450 
17. Hatipoglu Z, Gulec E, Lafli D, Ozcengiz D. Effects of auditory and audiovisual presentations on anxiety and behavioral changes in children undergoing elective surgery. Niger J Clin Pract. 2018;21 (6):788-794. doi:10.4103/njcp.njcp 22717

18. Gonçalves LL, Voos MC, Almeida M, Caromano FA. Massage and storytelling reduce aggression and improve academic performance in children attending elementary school. Occup Ther Int. 2017;1-7. doi:10.1155/2017/5087145

19. Moghimian M, Akbari M, Moghaddasi J, Niknajad R. Effect of digital storytelling on anxiety in patients who are candidates for open-heart surgery. J Cardiovasc Nurs. 2019;34(3):231-235. doi:10.1097/JCN.000 0000000000569

20. Zarei Kh, Parandeh Motlagh Z, Seyedfatemi N, Khoshbakht F, Haghani H, Zarei M. Impact of narration on physiological, worry and social anxieties in hospitalized school-aged children. Med-Surg Nursing Journal. 2013;2(3,4):115-121.

21. Tabrizi JS, Seyedhejazi M, Fakhari A, Ghadimi F, Hamidi M, Taghizadieh N. Preoperative education and decreasing preoperative anxiety among children aged 8-10 years old and their mothers. Anesthesiol Pain Med. 2015;5:4.

22. Rice M, Glasper A, Keeton D, Spargo P. The effect of a preoperative education programme on perioperative anxiety in children: an observational study. Pediatric Anesthesia. 2008;18(5):426-430. doi:10.11 11/j.1460-9592.2008.02490.x

23. Messina M, Molinaro F, Meucci D, et al. Preoperative distraction in children: hand-held videogames vs clown therapy. La Pediatria Medica E Chirurgica. 2014;36:5-6. doi:10.4081/ pmc.2014.5
24. Aytekin A, Doru Ö, Kucukoglu S. The effects of distraction on preoperative anxiety level in children. $J$ PeriAnesthesia Nurs. 2016;31(1):56-62. doi:10.1016/j.jopan.2014.11.016

25. Al-Khotani A, Bello L, Christidis N. Effects of audiovisual distraction on children's behaviour during dental treatment: a randomized controlled clinical trial. Acta Odontol Scand. 2016;74(6):494-501. doi:10.1080/00016357.2016.1206211

26. Al-Yateem N, Brenner M, Shorrab A, Docherty C. Play distraction versus pharmacological treatment to reduce anxiety levels in children undergoing day surgery: a randomized controlled non-inferiority trial. Child Care Health Dev. 2016;42(4):572-581. doi:10.1111/cch.12343

27. Majzoobi M, Amani R, Majzoobi F. Effects of psychological preparation on reduction of surgery anxiety signs in children. Koomesh. 2013;14(4):466-473.

28. Hudson BF, Ogden J. Exploring the impact of intraoperative interventions for pain and anxiety management during local anesthetic Surgery-A systematic review and meta-analysis. J PeriAnesthesia Nurs. 2016;31(2):118-133. doi:10.1016/j.jopan.2014.11.012

29. Gaskey N. Evaluation of the effect of a pre-operative anesthesia videotape. Aana J. 1987;55(4):341-345.

30. Fortier MA, Bunzli E, Walthall J, et al. Web-based tailored intervention for preparation of parents and children for outpatient surgery (WebTIPS): formative evaluation and randomized controlled trial. Anesth Analg. 2015;120(4):915. doi:10.1213/ANE.0000000000000444

31. Batuman A, Gulec E, Turktan M, Gunes Y, Ozcengiz D. Preoperative informational video reduces preoperative anxiety and postoperative negative behavioral changes in children. Minerva Anestesiol. 2016;82(5):534 542.
Pediatric Health, Medicine and Therapeutics

\section{Publish your work in this journal}

Pediatric Health, Medicine and Therapeutics is an international, peerreviewed, open access journal publishing original research, reports, editorials, reviews and commentaries. All aspects of health maintenance, preventative measures and disease treatment interventions are addressed within the journal. Practitioners from all disciplines are invited to submit their work as well as healthcare researchers and patient support groups. The manuscript management system is completely online and includes a very quick and fair peer-review system. Visit http://www.dovepress.com/testimonials.php to read real quotes from published authors. 